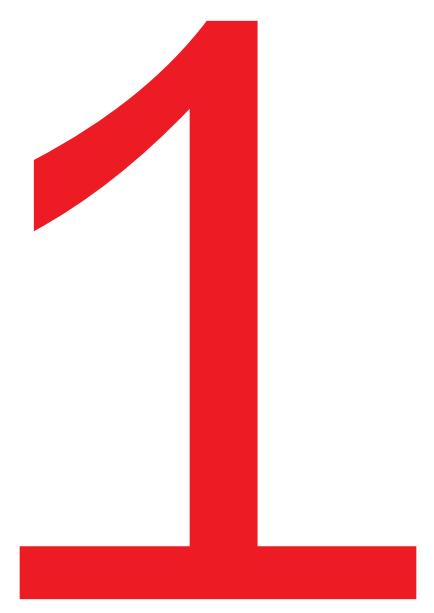

\title{
Abstract
}

This paper discusses progressive thinking and clinical views on improving mental health practice for immigrants and refugees. It addresses policy, care delivery, professionals' attitudes, and immigrants' access to mental health care - all factors especially pertinent for practice in major immigration hubs. The data was gathered from invited presentations and discussions among participants at an international multidisciplinary symposium, including health and social scientists from Toronto (Canada) and Paris (France), major urban centres attracting large numbers of immigrant and refugees who constantly encounter challenges for their successful settlement. The focus is on alternative care thinking and innovative approaches for better care and understanding of these populations' health behavior. Recommendations on how to advance knowledge relevant for these two urban hubs of immigration were documented, underpinned by the consensus that economic disparities, societal and political forces, as well as cultural and linguistic factors, influence immigrants' and refugees' vulnerability regarding mental health stability.

Key Words immigrant health, immigrant settlement, international collaboration, mental health, refugee health

\section{Immigration, settlement process and mental health challenges of immigrants/ refugees: Alternative care thinking}

\author{
MARGARETH SANTOS ZANCHETTA, ABINET \\ GEBREMARIAM, DAVID AFTAB ANSARI, \\ ELIZABETH HUANG, STÉPHANIE LARCHANCHÉ, \\ CLÉMENT PICOT-NGO, MARGUERITE COGNET, \& \\ SHONE JOHN
}

\section{Introduction}

At the dawn of the 21st century, health needs and problems have evolved considerably, alongside lengthening life spans, new trends in health behaviours, and unimaginable medical discoveries. According to Cognet (Symposium Opening Remarks, May 23rd, 2017), today's challenges reside within a triad comprised of global health, global economy, and local practices. A global health perspective involves uncovering health problems that are situated beyond individuals to address human groups, and that transcend state and territorial borders to address transnational health concerns. Addressing health security within a global economy requires attending to neoliberal development policies and the imposition of norms from the dominant economic models. Local practices remain and will continue to remain within the context of a territory, a social space where a culture is materialized by locally accepted roots. This is evident in every situation of an ill individual within the singular, clinical encounter with a healthcare professional.

This context is particularly relevant given the global phenomenon of a high level of voluntary and involuntary migration of people. Acknowledging these challenges, an international multidisciplinary symposium was organized and attended by health and social scientists from Ryerson University (Toronto, Canada) and Université Denis Diderot (Paris, France). Both cities, Toronto ard Paris, are major immigration hubs with high concentrations of resident migrants. Among the overarching themes of the symposium 
Health and Societies: Interdisciplinary Thinking within Interethnic Contexts (May 23-26, 2017, Toronto, Canada), was immigrants' and refugees' mental health and social vulnerability in the settlement process.

A recent United Nations report indicated that there were 258 million international migrations in 2017, and the Global North hosted $57 \%$ of them.[1] Immigrant and refugees refer to foreign born or foreign citizens whose trends in moving to another country do unfold mainly within the four more common corridors: Asia-to-Asia; Europe-to-Europe; Latin America and the Caribbean to Northern America; and, Asiato-Europe corridor.[1] Such international move is no more related uniquely for economic needs and related to age and gender since women accounts in 2017 for 48.4 per cent of all international migrants worldwide.[1]

Canada and France have been among the major destination countries for immigrants and refugees. According to the 2016 census of Statistics Canada,[2] there were 7.5 million immigrants in Canada, and of these 1.2 million immigrated between 2011 and 2016. Foreign-born individuals constituted $21.9 \%$ of the country's total population.[2] France officially had 6.2 million immigrants and 4.4 million foreigners,[3] of which $38 \%$ were Western European nationals, and 2.7 million were nationals from low- and middle-income countries in 2015.[4] For the whole of 2017, asylum applications reached 100,412, an increase of $17 \%$ compared to 2016 . The requests mainly concerned Albanian, Afghan, Haitian, Sudanese, Guinean and Syrian nationals.[5]

The extant literature shows that migration-related experience provokes emotional and mental instability among re-settled immigrants.[6] Although there is a dearth of literature on the pre-migration mental health state of immigrants,[7] existing evidence has identified the peculiar risks and exposures that trigger mental health challenges along the migration trajectory. Individuals' vulnerability to depressive disorders may increase due to war trauma, violence, and forced displacement experienced in the pre-migration phase.[6,8-9] During the migration process, a dangerous migratory path, uncertainty about legal residence status in the host country, and different forms of structural violence tend to undermine the mental stability of immigrants.[8] In the settlement phase post-migration, social isolation, the transition toward a lower or lowest socio-economic status and dealing with cultural differences jeopardize the mental stability of immigrants. [8,10-11] The different forms of institutional and structural violence, language barriers, as well as difficulty accessing the healthcare system may culminate in emotional instability.[710,12]
Data on the mental health of migrant populations in France is scarce,[13] but according to the Comité pour la santé des exilés[14] psychological and psychiatric disorders are the main cause of serious morbidity among immigrants. Trends in psychiatric epidemiological research among immigrant populations in France suggest that there is an increased risk of psychosocial vulnerability associated with migration status and being an ethnic minority.[15] A study has shown that migrant status in France increases the risk of depressive disorders, bipolar disorders, post-traumatic stress disorder, substance and alcohol abuse and drug dependence, regardless of socio-economic status or geographical origin.[16] Immigrants, especially those who are undocumented, may develop a combination of psychological, social, and administrative vulnerabilities that have a significant impact on their mental health.[17] International evidence indicated that undocumented immigrants typically lack access to basic preventative, diagnostic services, resulting in undiagnosed diseases, or diseases diagnosed in later and more advanced stages.[18-20] Like other immigrants, these individuals may also encounter threats to their mental health and wellbeing such as family separation, exposure to traumatic events, discrimination, and loss of social status. The fact of having an "illegal" status restricts access to opportunities, obstructs societal integration, limits social support, and challenges immigrants' self-identity.[21] In Canada, the incidence of mental illness (post-traumatic stress disorder, depression) and the risk for psychosis and emotional issues is higher among refugees when compared to the overall national immigrant population.[22-23]

\section{Theoretical framework}

The "structural vulnerability " theoretical framework is widely used in medical anthropology. It relates to the fact that health involves far more than just the presence or absence of disease, and that the social determinants of health - that is, the upstream factors and structural conditions that predispose certain individuals and communities to be healthy in the first place - are paramount to an individual's physical and mental well-being. Ethnographies have taken a critical look to how the social context of migration shapes chronic disease, mental health in particular.[24-26]

Until recently, public health policy related to immigration has seldom acknowledged social determinants such as housing and living conditions, access to welfare services, and administrative hardships. Medical anthropologists have therefore encouraged public health practitioners and policymakers to examine immigration "as both socially 
determined and a social determinant of health".[27, p376] Rather than depicting migrants as an at-risk population, which places responsibility on individuals, researchers argue it is preferable to identify immigrants as "structurally vulnerable". [28] For professionals, recommendations for practice included relying on a "structural competency" approach that engages medicine with stigma and inequality.[26,29-31] This argument has been succinctly summarized:

It is not solely a matter of training and sensitizing individual health practitioners to 'see' their patients as structurally vulnerable, but also a question of establishing viable institutional practices that encourage health practitioners to fulfill their roles as genuine healers. Insisting that both health practitioners and the systems they work within include structural vulnerability as an etiologic agent in the presenting signs and symptoms that they daily confront pushes medicine to extend its purview towards becoming more fully social and more responsive to underserved populations.[28, p9]

From that perspective, multidisciplinarity was highlighted as key approach to acknowledging "structural vulnerability" in health practices.[26,32] It is necessary to emphasize that in this paper, the multidisciplinary approach is defined as an approach that applies the concomitant professional provision of care and services, such as, by law, psychiatry, psychology, social work, nursing, etc. to address the particularities and needs of the immigrant and refugee populations.

Therefore, in this paper we discuss the conceptual integration of "social/structural vulnerability" in mental healthcare delivery models, based on the ideas exchanged by the Symposium participants (i.e., academics in the health and social sciences, business faculty, researchers, undergraduate and graduate students, as well as community stakeholders) and evidence that has emerged from research programs and practitioners' experiences in both countries. The focus is on the role of a multidisciplinary approach that incorporates evidence from social scientific research in the delivery of primary mental healthcare for immigrant and refugee populations. Our analysis was guided by the question: From a synergy between the health and social sciences, what new ideas emerged from the dialogue between Toronto and Paris researchers and health practitioners for innovation in mental health care for immigrants and refugees?

\section{Methods}

The raw material and data for analysis was the content of the Symposium's invited presentations-a combination of presenters' experiential knowledge and research program. Contents for analysis were retrieved from five of the round- table discussions that were held on various aspects of the mental health of immigrant and refugee populations:

-Dimensions of vulnerabilities in health experiences (Round Table \#2)

-Complex, chronic diseases in the context of immigration: situations lived by minorities (Round Table \#4)

-Multidisciplinary methods and approaches: field experiences (Round Table \#5)

-Foreseeing future collaborations between Toronto \& Paris: discussion with Ryerson research collaborators (Round Table \#6)

-Migration and settlement policies and experiences (Round Table \#7)

To identify the targeted contents, the following procedures were used:

-Listen to the audio files of five round tables for retrieval of content on mental health issues in the discussants' experiences, professional approaches, and policies. Attentive listening to grasp the emotional context of the discussions held among presenters and audience;

-Review of the audio files, transcribed to select the most illustrative parts of verbatim speech to be used in the manuscript;

-Review and summary of the Symposium's final clusters of discussed ideas;

-Manual retrieval of content for analytical discussions;

-Review of connections between the main ideas shared and discussed in the Symposium with the professional practice of co-authors with immigrants and refugees in Paris and Toronto.

Upon selection of six presentations that addressed the target content, special attention was given to presenters' experiential knowledge and scientific evidence as raw material for analysis. The analytical procedures were inspired by the method of thematic analysis[33] using the following steps: (a) transcribed texts were intensively read and emerging ideas noted; (b) a preliminary list of themes was prepared to guide further readings of the texts; (c) analytical concepts that highlighted affinities and contradictions among themes were highlighted, and defined the thematic axis; (d) reflections were logged during readings of the texts and attempts to group the themes with a focus on the key themes and content that tentatively answered the research/analytical question. From this analysis four analytical themes emerged: (a) Mental health 
challenges post-migration; (b) Improving migrant populations' access to care: alternative care thinking; (c) The big picture: mental healthcare delivery, social context and public policies; (d) Immigration/Asylum, settlement process and mental health challenges: clinical perspective from Toronto and Paris.

\section{Results}

Foremost it should be noted that prior to the Symposium no round-tables with prepared documents were held. During the Symposium sessions, the discussions were spontaneous within the scheduled duration of two hours each. The content primarily addressed comparisons between practice in Paris and Toronto, with reflexive remarks on transnational issues, and challenges and threats faced by immigrants/refugees regardless of their age, nationality, language, and sexual orientation. Review of the recorded discussions did not reveal any polarized positions, as evidence of the Symposium emotional climate and degree of consensus.

In the following sections, we present selected content that outlines our analysis and illustrates the four analytical themes, using direct quotations by various presenters. While comments from the audience were not part of this analysis, some of them were introduced here to corroborate some argumentative statements.

\section{Mental health challenges post-migration}

The available evidence supports the link between migration and mental health challenges.[7-10,34] Building on Newbold's[35 p1366] contention that "the foreign-born is at increasingly greater rate of experiencing poor health relative to the native born over time", Dr. Kwame McKenzie's (psychiatrist, Centre for Addiction and Mental Health, Canada; Presentation title: Centre for Addiction and Mental Health's work -Round Table \#6 ) presentation discussed how the "healthy immigrant" effect is lost over time among immigrants in Canada. While only 4\% of immigrants arrive in Canada with long-term diseases or chronic illness compared to $9 \%$ of Canadian-born individuals, seven years post-arrival, immigrants are in worse health compared to the general population. He emphasized how social determinants of health such as unemployment, low-end jobs, workplace policies, low service use, language barriers, discrimination, and stigma associated with mental illness may increase risk for mental illness of immigrants, refugees, and ethno-cultural and racialized (IRER) populations in the province of Ontario, Canada. Recent immigrants are more likely to be unemployed, have a low income, and be in need of housing. In Canada, IRER groups are more exposed to the social forces that promote mental health problems, and have poorer access to treatment services and poorer outcomes. There are no plans in effect to deal with the existing barriers to service or promote more equitable access (Dr. K. McKenzie,
May 25 2017).

Based on her clinical practice as a midwife, Professor Manvi Handa (midwife, Ryerson University, Canada, Presentation title: Uninsured pregnant women: understanding vulnerabilities and addressing health care access - Round Table \#2) analyzed the high incidence of psychiatric issues among uninsured pregnant newcomer women in Toronto, as an example of lived vulnerabilities and restricted access to healthcare for undocumented refugees.

Many newcomers are actually women of childbearing age. There is a high incidence of psychiatric disorders compared to general population, particularly around anxiety and depression, and much lower health-seeking behavior for psychological issues. So, individuals are more likely to suffer depression and anxiety and less likely to get help when they have those conditions. (Prof. M. Manda, May 23, 2017)

Dr. Simeng Wang (sociologist, National Center for Scientific Research, France, Presentation title: The use of alternative care in mental health: the case of Chinese immigrants undergoing psychiatric care - Round Table \#4) presented a case from her ethnographic study in Paris where Chinese immigrants under psychiatric care also consult traditional Chinese medicine. Although many French-origin doctors are also trained in Chinese medicine, the patients preferred practitioners of Chinese origin.

It is quite rare to see a Chinese patient who consults a practitioner who is not of Chinese origin. This patient is looking for the prescriptions of the Chinese pharmacopoeia and acupuncture care. There are some patients in particular who talk about linguistic barriers that are felt in relation to French caregivers. There are some who prefer to speak or consult directly in Mandarin. As one of the patients said, "If it is someone who does not speak the Chinese language or who has never prepared Chinese food, how can I trust him? How can he treat me with the medicine that comes from my country?" (Dr. S. Wang, May 24 2017)

Dr. Wang emphasized the importance of introducing social science knowledge to health professionals, especially psychiatrists, and of incorporating ethnic and inter-cultural brokerage (including language brokerage) in therapeutic relationships.

\section{Improving care access for migrant populations: alternative care thinking}

During the Symposium, participants argued that the conventional approach to cultural competence, when reduced to cultural expertise, leads to essentialist understandings of particular cultures and their conflation with race and ethnicity,[36,37] which is particularly problematic in primary mental healthcare for immigrants. Therefore, an alternative way of thinking, approaching and caring this population was endorsed by the participants and was identified as one of the 
analytical theme.

Scholars have shown that more nuanced uses of cultural competence are required, especially in response to cultural diversity in psychiatric practice.[38-40] Given the complexity of cultural diversity, immigration, and settlement, the context of clinical encounters with culturally diverse clients provoke multiple layers of uncertainty among healthcare providers (HCPs) about how to best support clients with whom they do not share a language or culture. Clients may also have different narratives of their experience with mental illness, or extremely unstable living conditions-in terms of legal status, stability of housing and work, and connectedness in their host societies. Indeed, linguistic, cultural, and social factors can have a profound effect not only on the expression of mental suffering, but also treatment of mental illness.

The Symposium participants emphasized the various vulnerabilities that immigrants encounter regarding access to mental health care. From a policy perspective, Dr. McKenzie corroborated this observation by pointing out the absence of a government plan to deliver mental health services to IRER groups in a more equitable way. He particularly pointed out the need for a culturally competent healthcare system, which is acknowledged in the Canadian National Mental Health Strategy. This strategy could facilitate equitable access to care, though its implementation is questionable, as he said, "Nothing has happened since [its development]". Taking culture into consideration, his research team has developed a culturally tailored Cognitive-Behavioral Therapy (CBT) tool for anxiety and depression that can be adapted for different cultural groups (it has already been tailored for Caribbean, Francophone Caribbean, and African Francophone populations).

From a care delivery perspective, Dr. Elodie Grossi (sociologist, Université Denis Diderot, France, Presentation title: Racialized landscapes in mental health care in San Francisco Bay Area: The Department of Psychiatry in UCSF, 1980-2005 - Round Table \#4) discussed how cultural competence has been thought to be achieved through the ethnolinguistic/ethnoracial pairing of clients and HCPs. In 2016, she conducted a socio-historical qualitative study that focused on the work conditions and the modalities of care developed within the Department of Psychiatry at the University of California, San Francisco, USA. Patients were categorized mainly by ethnicity (i.e., Asian origin, African Americans, Latinos, and Caucasians). HCPs from the same ethno-racial background would manage the patients.

One of the rationales for establishing the care management by such "units" was to minimize the language barrier between HCPs and their patients and families (this argument could not be extended though for having a separate unit for African Americans who speak English). It was argued that such ethnoracial organization of care would help create and define a safe therapeutic space that is symbiotic with the patients' macroculture. The ethno-racial pairing was believed to facilitate a trusting relationship between the HCPs and patients and that psychiatrists would understand the cultural nuances of their patients. One of the study's participating psychiatrists explained how the concept of culture was viewed as a proxy or tool to facilitate the effectiveness of care:

There are a lot of trust issues between the patients and the psychiatrists, and we do not have six months to work together and build trust, yet there is a need to find a way to engage to create a space....a relationship of trust fairly fast. Culture is a way to accelerate the efficacy of support...." (Dr. E. Grossi, May 24 2017)

Another argument was that psychiatric diagnosis evolves according to the culture and race of patients as identified in Grossi's study. Another of Grossi's study participants explained that at times there might be poor diagnosis or forced diagnosis when psychiatrists misunderstand behaviors that are not signs of mental deviance in certain cultures (for example, hearing the voice of God). Another participant in Grossi's study made a clear distinction between cultural fluidity and biomedical certainty:

...diagnosis and drug management are different things. For the diagnosis, we can understand it, not in a physiological way but in a cultural way. On the other hand, for all medical prescriptions, we turn to biomedical [explanations].

While some practitioners in Grossi's study agreed that cultural awareness diminished the likelihood of over-diagnosis or misdiagnosis of psychiatric illnesses,[41] their culturematching approach stoked controversy, to the extent such ethno-racial segregation was denounced as "psychiatric apartheid." Symposium presenters and participants reiterated that, particularly in North America, the concept of "cultural competence' is influential in practice and education. It is believed that HCPs may attenuate the uncertainty they face regarding their patients' practices, beliefs, and attitudes by enhancing their cultural knowledge and understanding in order to address their patients' particular needs.[42]

Sociologists have offered classic descriptions of how uncertainty is inevitable in cross-cultural understandings, and have claimed that HCPs should define measures to attempt to manage it.[43,44] This is the basis for arguing that primary mental healthcare should move from an interdisciplinary (health) model to a social science-inclusive multidisciplinary 
care delivery model.

Proposed as an innovative approach, Dr. Margareth Zanchetta (nurse, Ryerson University,Canada)and Mohamed Mohamed[6] (nurse, Toronto Public Health, Canada) presented their work with Dr. Stéphanie Larchanché and Dr. David Ansari, which illustrates how the mental health delivery model practiced at the Minkowska Centre in Paris (Centre Médico Psychologique Françoise Minkowska) go beyond simplistic notions of cultural differences. In this model, developing expertise in cultural understanding is considered to be more of a process of social construction, rather than based on the psychiatrist's scientific knowledge and technical skills. The Centre's multidisciplinary team intentionally adopted the concept of "mental suffering" rather than psychiatric diagnosis, taking into consideration cultural differences and social determinants (immigration trajectory, legal status, housing, employment, etc.) to understand health and illness. The focus at the Minkowska Centre is on analyzing how psychiatrists, psychologists, social workers, anthropologists, nurses, students and trainees use their professional skills. Until the mid-1990s, the care of immigrant and refugee patients in France was generally organized around their linguistic and cultural origin, following a culturalism approach (similar to the ethno-racial pairing logic described above by Grossi).[45] However, considering the ideological context of Republican France, which highlights universal values, such a culturalist approach became highly controversial. Recognizing the limitations of this approach and its stigmatizing consequences, for both patients and clinicians, the Minkowska Centre incorporated concepts and interpretations of illness derived from clinical medical anthropology (referred to as AMC in French: anthropologie médicale clinique) to guide the practice of health and social professionals who work with individuals from diverse cultural and linguistic backgrounds.[46,47]

This approach was based on Kleinman's model of illness, sickness and disease,[48] which values and incorporates the individual's own comprehension and expression of psychological suffering, including cultural representations that are articulated according to what some consider magicalreligious, spiritual and/or traditional values, as well as the client's status and circumstances. Using this approach, the professionals together with clients at the Minkowska Centre explore language competence, immigration trajectory, exile history, notion of trauma, and medication regimen, as well as clients' expressions and understanding of their mental suffering. Cases are considered complex, not only due to their linguistic and cultural features, but also because of the negative, cumulative impact of social factors such as lack of legal status, stable housing, unemployment, etc. Mutual learning occurs intra-team and knowledge confrontation helps to construct or deconstruct knowledge. This approach to mental suffering management is unique since it centers on the client's well-being and stresses cultural inclusiveness. The Minkowska Centre is also exceptional for the multidisciplinary profile of its mental healthcare team, including the presence of health anthropologists who contribute to the understanding of illness from ethnographic perspectives.

In addressing the emotional and mental suffering of individuals within their trajectory of international relocation, Kleinman's ideas,[48] which differentiate between disease and illness and their specific role in the cultural process of explaining sickness, are supportive of the multidisciplinary approach proposed in this paper. Kleinman's definition and conception of illness incorporates an individual's grassroots concepts as valid clinical realities, and stresses the role of an explanatory model (EM), of transactions in healthcare relationships, of cultural healing and cultural iatrogenesis, and the core adaptive task of healthcare systems. Taken together, this approach offers a meaningful theoretical framework for clinical practice, public health work and research.

According to Kleinman,[48 p88] disease signifies a "malfunctioning in or maladaptation of biological and/or psychological processes", and illness implies the experience of (perceived) disease and the societal reaction ascribed to the disease. Disease is generally associated with the EMs of HCPs and the conventional healthcare culture in which theories of disease causation and nosology are presented in an abstract manner, while illness is predominantly linked with the EMs of clients and their understanding of their illness within their cultural milieu and experience. A culturally-constructed struggle may arise when HCPs perceive sickness only as a disease and provide technical information and explanations for treatment, while clients require more than just assistance with managing their symptoms: they expect personally and socially meaningful explanations and psychosocial treatment. For example, an asylum-seeking patient suffering from PTSD, and interpreting the presence of her aggressor through flashbacks as a act of sorcery, may expect the mental HCPs to accompany her meaning-making journey through the symptoms, beyond providing medication. Meanwhile, it is paramount for the mental HCP to be able to distinguish between what they may readily interpret as a sign of hallucination based on a biomedical EM, and a culturally-specific way to interpret a symptom from the perspective of the client's own EM. This client-centred model of cognitive transactions in healthcare stresses the role that cultural understandings play in shaping 
the decisions and evaluations of medical treatment - both for HCPs and for patients.[48]

Following the input of $\mathrm{AMC}$, the Minkowska Centre revised its intake criteria so that individuals were no longer triaged or referred to the Centre's clinicians solely on the basis of their culture or language of origin. In 2009, the Médiacor model was conceived and implemented by Dr. Rachid Bennegadi (psychiatrist) and Marie-Jo Bourdin (a social worker) in the Minkowska Centre.[47] Its goal is to facilitate efficient orientation of patients by focusing on person-centered care (rather than culture-centered care), thus making it less stigmatizing.[49] As the Médiacor model developed, Centre staff started providing support and feedback to the referring institutions, enabling them to evaluate their own social/clinical practices and make changes as needed.

Figure 1 illustrates the conceptual framework of the Médiacor model as a perspective for actions for mediation, reception and orientation.[49] Its operationalization unfolds by a circle of dialogue including client, family members, social service and health providers, and the Médiacor team.

The person-centered mental care approach of this model enables HCPs to move away from ethnocentrism and stigma toward contemporary applications of cultural competency. The core of the multilayer approach is the mental health of the individual and strengthening their self-defense mechanisms to promote their emotional/mental well-being. The interventions implemented according to this model are grounded in scientific evidence, the clinical care provided by psychotherapy, and the experiential knowledge of the HCPs and social service professionals.

Within these three major dimensions, interactions aim at the professional development and mobilization of technical competencies. They are intertwined with clinical interventions that integrate various dimensions of the clients, namely their way of life, spirituality, life story, as well as biological aspects. In this model, culture is a paradigmatic concept to establish a concrete intercultural management project among clients', families' and professionals' interests. In this model of caring, the transactional view of culture inspires professional training, informs the clinical framework, and shapes the helping process to promote clients' coping skills and consequent resilience (for examples of ethnographic illustrations of how MEDIACOR is enacted, see Larchanché[26]).

Having been a research intern using the Médiacor model in 2016, M. Mohamed (Presentation title: Which professional expertise for intercultural care? Experiences of a mental health multi-disciplinary approach at the Minkowska Centre, Paris - Round Table \#5) drew on his experiential knowledge to present his reflections about the possible ways to use a similar approach in Toronto to innovate practice with immigrants/ refugees:

-Healthcare providers should be comfortable with the idea of building a trusting relationship based on person-toperson connection.

-Open dialogue about mental conditions does not undermine trust, patient's adherence and family participation.

-Use of plain language ensures clear communication and respects the patient's autonomy in choosing levels of intervention.

-Power sharing is possible and non-threatening to professionals.

-Truth is ethically shared and transparency is part of the

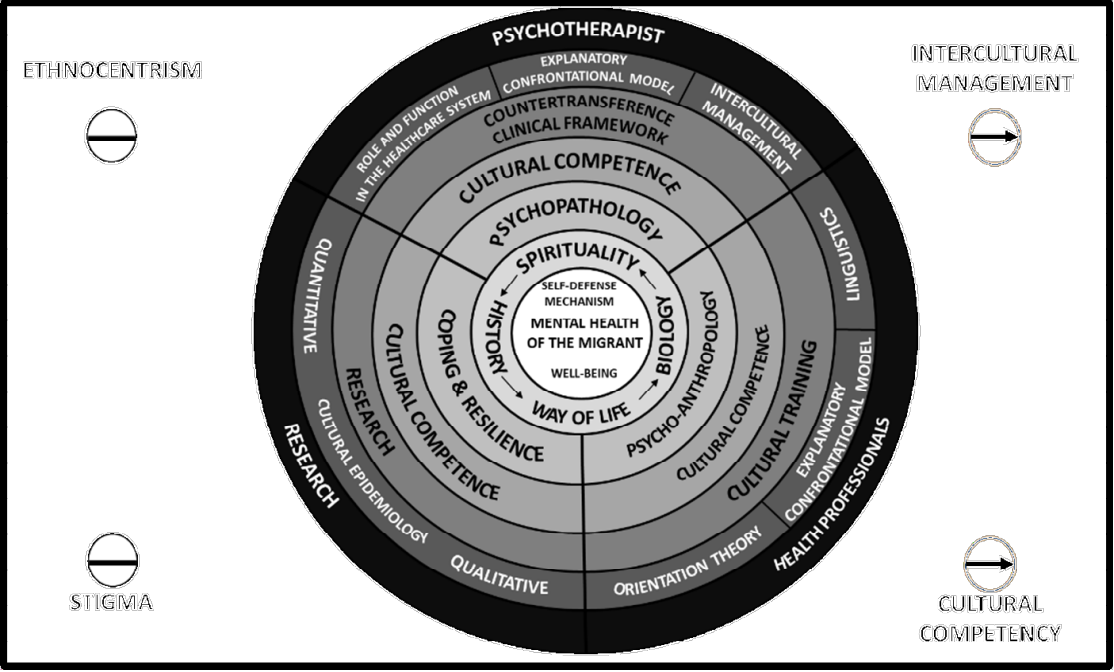




\begin{tabular}{|c|c|c|c|}
\hline $\begin{array}{l}\text { Settlement process chal- } \\
\text { lenges }\end{array}$ & $\begin{array}{l}\text { Awareness of mental } \\
\text { health }\end{array}$ & $\begin{array}{l}\text { Search for treatment due to psychiat- } \\
\text { ric diagnosis }\end{array}$ & Access to health care \\
\hline $\begin{array}{l}\text {-Individuals typically face } \\
\text { a lot of hurdles in terms of } \\
\text { seeking appropriate treat- } \\
\text { ment. } \\
\text {-Housing: refugee status } \\
\text { individuals typically start } \\
\text { settling in Canada in group } \\
\text { shelters with upwards of } \\
600 \text { individuals. It can take } \\
\text { up to a year before they } \\
\text { are able to get reasonable } \\
\text { accommodation. } \\
\text {-This clustered housing } \\
\text { situations leads to greater } \\
\text { exposure to infections and } \\
\text { unhygienic living condi- } \\
\text { tions. } \\
\text {-Group housing also adds } \\
\text { to hopelessness and } \\
\text { housing insecurities, which } \\
\text { result in added mental an- } \\
\text { guish and plausibly more } \\
\text { mental health issues. }\end{array}$ & $\begin{array}{l}\text {-Mental health is a highly } \\
\text { stigmatized concept for } \\
\text { many immigrant communi- } \\
\text { ties (notably, Asian, African, } \\
\text { Eastern European and } \\
\text { South American ones). } \\
\text {-Considerable fear about } \\
\text { community/familial blow- } \\
\text { back from being associated } \\
\text { with psychiatric conditions. } \\
\text {-Fundamental lack of knowl- } \\
\text { edge regarding mental } \\
\text { health in immigrant com- } \\
\text { munities. }\end{array}$ & $\begin{array}{l}\text {-Reluctance in accepting medical } \\
\text { diagnosis. } \\
\text {-Preference for pharmacological in- } \\
\text { tervention over psychological therapy } \\
\text { (like cognitive behavioural therapy, } \\
\text { psychotherapy, dialectal training etc.). } \\
\text {-Psychotherapy is viewed in a negative } \\
\text { light } \rightarrow \text { the connotation is that it is a } \\
\text { pseudoscience and the diseases as- } \\
\text { sociated with them are not legitimate. } \\
\text {-When taking pharmacological treat- } \\
\text { ments, there is often non-compliance } \\
\text { with dosing regiments. } \\
\text {-Difficult management of expectations } \\
\text { regarding “cure". } \\
\text {-Families typically struggle to under- } \\
\text { stand degenerative diseases such as } \\
\text { Parkinson's and Alzheimer's diseases. } \\
\text {-The belief is that there should be a } \\
\text { complete cure and the person should } \\
\text { get back to baseline health. } \\
\text {-Often frustration when a loved one } \\
\text { fails to return to their “normal selves." } \\
\text {-Often avoid seeking treatment. } \\
\text { Contact is lost during follow-up pro- } \\
\text { cess and procedures. }\end{array}$ & $\begin{array}{l}\text {-Refugees with Interim Federal Health } \\
\text { Program (IFH) have coverage for clini- } \\
\text { cal visits and medications. However, } \\
\text { not all clinics will accept IFH; there- } \\
\text { fore, these refugees are diverted to } \\
\text { charitable free clinics who will see } \\
\text { them and then be reimbursed for } \\
\text { services via the government. } \\
\text {-Undocumented immigrants, immi- } \\
\text { grants waiting for provincial health } \\
\text { cards and refugees without IFH do not } \\
\text { have coverage for clinic visits or medi- } \\
\text { cations and will incur the financial } \\
\text { burden associated with those events. } \\
\text {-Individuals must seek care from non- } \\
\text { profit charitable clinics who will see } \\
\text { them for free. } \\
\text {-Only } 11 \text { clinics in Toronto are no- } \\
\text { cost, with limited hours of operation, } \\
\text { and limited resources to assist the } \\
\text { refugee/undocumented immigrant } \\
\text { population, with a waiting time longer } \\
\text { than } 2 \text { hours. } \\
\text {-Difficulty of commuting is the single } \\
\text { biggest barrier to seeking help ( } 2-3 \\
\text { hours via transit. } \\
\text {-Little access for immigrant/refugees } \\
\text { located in rural communities. }\end{array}$ \\
\hline
\end{tabular}

work philosophy.

-Young children can take part in the decision-making process.

In this presentation, Dr. Zanchetta added that such an approach can allow clients to create a more trusting relationship with health/social professionals because of the openness of the process, its transparency, and the supportive environment that allows them to benefit from questioning or challenging EMs.

\section{The big picture: mental healthcare delivery, social context, and public policies}

If social vulnerability is a concrete, non-measurable indicator of sensitivities and response of a given group to threats and risks,[50] understanding social vulnerabilities is incomplete without taking into account the structural factors that affect many immigrants, both documented and undocumented.
In this context, Dr. John Shields (political scientist, Ryerson University, Canada, Presentation title; Migration and settlement policies in Canada - Round Table \#7) pointed out that

...in Canada, immigration policy rhetoric resonates the values of the political party in power. In the past decade, the Conservative party, for instance, accentuated immigrants' self-reliance in terms of settlement and integration, cutting funding for the settlement budget, as well as social and health benefit packages.

Such macro conditions introduce issues of structural violence and their effects. A physician and anthropologist, Farmer[51] illustrated how large-scale social forces, such as poverty and racism, can be translated into individual experiences of disease and distress. During the settlement phase, structural violence is most apparent where larger political forces directly or indirectly affect immigrants' and refugees' mental health outcomes and their access to healthcare services.[47] 


\begin{tabular}{|c|c|c|c|}
\hline Settlement process challenges & $\begin{array}{c}\text { Awareness of mental } \\
\text { health }\end{array}$ & $\begin{array}{c}\text { Search for treatment due to } \\
\text { psychiatric diagnosis }\end{array}$ & Access to health care \\
\hline $\begin{array}{l}\text {-Increasingly restrictive immigration and } \\
\text { asylum policies negatively impact immi- } \\
\text { grants' hosting conditions, which in turn } \\
\text { negatively impacts their mental health. } \\
\text {-The 'Dublin regulation' leads some } \\
\text { asylum seekers to find themselves in } \\
\text { liminal situations where they are unable } \\
\text { to apply for asylum when their entry was } \\
\text { recorded in a different European country. } \\
\text { The 'Dublined' are thus threatened with } \\
\text { deportation to the country of first entry, } \\
\text { and without access to housing or other } \\
\text { social services. } \\
\text {-Housing shortages for refugees cause } \\
\text { some asylum seekers to experience pre- } \\
\text { carious housing conditions or homeless- } \\
\text { ness. Some are housed in other regions } \\
\text { of France where access to healthcare and } \\
\text { social services is more limited, in part due } \\
\text { to lack of interpreter services. } \\
\text {-Emergency housing services are } \\
\text { recurrently saturated, and even priority } \\
\text { candidates such as families with children } \\
\text { struggle to access housing. }\end{array}$ & $\begin{array}{l}\text {-Mental health is a highly } \\
\text { stigmatized concept for } \\
\text { many immigrants. } \\
\text {-Mental healthcare is not } \\
\text { considered a priority when } \\
\text { the social and administra- } \\
\text { tive situation is precarious. }\end{array}$ & $\begin{array}{l}\text {-Occasional cultural } \\
\text { confrontations around the } \\
\text { meaning and origins of } \\
\text { psychological/psychiatric } \\
\text { disorders. } \\
\text {-Relevance of psychother- } \\
\text { apy debated: social issues } \\
\text { come at the forefront, more } \\
\text { pressing to clients than } \\
\text { their own state of health. }\end{array}$ & $\begin{array}{l}\text {-Asylum seekers have universal } \\
\text { health coverage, while undocu- } \\
\text { mented immigrants have access to } \\
\text { State Medical Aid (starting in the 4th } \\
\text { month of residence). } \\
\text {-Are eligible to access state-funded } \\
\text { health services, but face challenges } \\
\text { in mental healthcare because of sec- } \\
\text { tor-based organization: some clinics } \\
\text { may turn down referrals when there } \\
\text { is no proof of stable residence. Only } \\
\text { a few mental health clinics are not } \\
\text { sector-based (such as Minkowska). } \\
\text {-A majority of hospitals and clinics } \\
\text { are reluctant to resort to profes- } \\
\text { sional interpreters in France, which } \\
\text { limits healthcare access for non- } \\
\text { Francophone immigrants. } \\
\text {-Most transcultural clinics and } \\
\text { interpreter services remain central- } \\
\text { ized in the Paris area, which limits } \\
\text { healthcare access for immigrants in } \\
\text { other regions. }\end{array}$ \\
\hline
\end{tabular}

Elaborating on this impact, Dr. K. McKenzie discussed some of the policy, planning and resource allocation-related concerns in relation to mental health services for immigrants in Ontario, Canada:

There is no plan to actually serve other (immigrant) populations in an equitable way.... Our work shows [there is] an increased risk [among] immigrants compared to non-immigrants.... We spend less money on mental health services [for immigrants than nonimmigrants]. (Dr. K. McKenzie, May 25 2017)

Throughout the Symposium, immigrants' and refugees' mental health issues were intensively discussed within the perspective of a cluster of clinical ideas. Among them was the psychology of suffering; the need to re-frame the physicianclient relationship from the client's perspective and to recognize challenges established by cultural insensitivity and power dynamics; the process of negotiating cross-cultural differences while regarding expectations of the communication of medical information; as well as the strategies needed to reach out to these dispersed populations.
Immigration/Asylum, settlement process and mental health challenges: clinical perspectives from Toronto and Paris

The Symposium led us to review the clinical perspectives of mental health services through the lens of daily practice in Toronto and Paris. Tables 1 and 2 present the major features of the clinical perspectives, as witnessed by the co-authors who are also practitioners. Three key actions are proposed to address the issues in listed in the Toronto context: (1) Develop initiatives that are culturally sensitive, which would go a long way in knowledge and skill development; (2) Design electronic health sources in various languages, as appropriate; and (3) Adopt an integrated approach that includes family members, which would also be fruitful in educating all stakeholders involved. The key actions proposed to address the issues listed in the Paris context are: (1) Promote more extensive and frequent interprofessional and interagency collaboration initiatives (an example would be the monthly Réunion de Concertation Pluridisciplinaire en Périnatalité in the Aquitaine region); (2) Develop health interpretation and mediation, in accordance with recommendations of the Haute Autorite 
de Santé (High Health Authority), and in a multidisciplinary research perspective; and (3) Train social/health professionals on the transcultural competence model that promotes the multidisciplinary collaboration model described above, and work with interpreters.

\section{Discussion}

The Symposium presenters and other participants discussed how refugees, asylum seekers, and conventional and unconventional immigrants are exposed to high risk for certain mental health ailments such as post-traumatic stress disorder, depression, psychosis and other perceived biological, emotional and cultural illnesses. Some of the greatest challenges for these populations living in host countries are the understanding and right channels to find an appropriate solution for their health issues. In the post-migration context, these challenges can be due to an individuals' lack of knowledge about their entitlement to care, their understanding of the host country's healthcare system, reading and spoken communication barriers, differing belief systems and cultural expectations for health care, and even a general lack of trust in professionals and authorities. This can present a seemingly complex set of problems that leaves many individuals without the proper guidance to obtaining appropriate, effective care that would sufficiently address their desired outcome.

Since appropriate professional guidance requires some sensitivity to the client's mental suffering, refining HCPs' technical competence is required, particularly their cultural competence.[52] While a version of cultural competence has been widely adopted and systematically integrated into medical training for professionals from several disciplines, especially in North America,[38-41] the dominant notion of cultural competence has drawn criticism and inspired critiques and debates among clinicians and social scientists for several reasons. Culture has been wrongly perceived to be a static assortment of traits shared by all members of a particular group.[36,39] Individuals have been perceived to be the bearers of culture, whereas HCPs and other social service professionals have been increasingly challenged to reflect on their own professional and personal background.[40,5354] This fixed notion of culture has led to a 'one size fits all' approach where cultural competence training is assumed to meet the needs of a heterogeneous population.[39,41] Culture has also been seen as a barrier to care that needed to be overcome, and an emphasis on cultural factors has overshadowed attention to the social determinants of health and the consequent health inequalities experienced by patients.[27,30,36,39,55,56]
Cultural competence has been defined as HCPs' understanding of cultural and social factors' that influence the health beliefs and behaviors of clients/patients, along with an understanding of how these factors interact at multiple levels of health delivery systems.[57] Some extended cultural competence may occur in cross-cultural encounters[39,57] added to one's cultural knowledge and understanding. As a result, alternatives to the dominant notion of cultural competence have been proposed, based on developing critical consciousness,[58] cultural humility,[59-61] cultural responsiveness,[62] cultural safety,[39] and structural competence.[31,63]

Scholars of immigration, notably those who examine restrictive immigration policies and deportation, describe how the status of illegality is experienced with the persistent and ongoing risk of apprehension and deportation.[64-67] These authors describe how undocumented immigrants live in fear of being apprehended, which seeps into their everyday actions so that any activity, no matter how mundane, potentially becomes illegal. Similarly, social science researchers in France have highlighted the difficulties encountered by newcomers in terms of access to housing and obtaining a permanent residence permit which is a prerequisite for access to other services and resources.[13,68] Institutional discrimination and the processes by which the State creates obstacles to the extension of residence permits and to obtaining refugee status exert violence in those populations that deteriorates their mental health.[69,70] The structural violence of reception policies in France is concretized in particular by the acceleration of evaluation procedures within the administration.[71]

Taking these perspectives together, restrictive immigration policies and the conditions of illegality represent a form of structural violence which may prevent immigrants from using the healthcare services they are entitled to, which in turn may lead to deteriorating mental health. In France, the care of precarious immigrants and refugees suffering from mental disorders is confronted with the saturation of the MedicoPsychological Centers.[72] In this context, language barriers are the main problem for non-French speakers (Allophones), non-English speakers and newcomers.[73] A study of 385 French general practitioners showed that communication problems were one of the main difficulties they encountered (55\%) in the care of precarious immigrants.[74] Yet, there is no public interpreting service in France except for a few interpretation services provided by non-profit organizations.[73] Faced with the difficulties of psychiatric care for immigrants, a project to coordinate progressive psychiatrists has been developed in Rhône-Alpes in order to overcome the phenomenon of saturation within public care 
Proposed research topics

-Addictions in the experiences of immigration and asylum seeking

-Alternative forms of knowledge production about the disclosure of mental health issues by and with immigrants and refugees (e.g., poetry)

-Configuration of social inclusion when targeted in mental health services for culturally diverse populations

-Deconstruction of the image of race and culture and their effects on mental health

-Gender and religious effect(s) on perceptions of mental and physical health

-Images/art by patients plus other forms of expression

-Pathways of patient immigration/refugee journey

-Review of construction of knowledge in current paradigms

-Suffering as a cultural representation of patient experiences

-Technological disruption and mental health

-Use of art in mental health therapy

structures. This project highlighted several organizational difficulties, including ongoing very limited access to freelance interpreting.[75]

In Canada, former and current immigration policies determine the number and category of immigrants admitted to the country, as well as their settlement and integration experiences.[76] Historically, Canada's immigration policy was shaped by the country's self-interest (economic, demographic and cultural) rather than humanitarian ideals. Towards of the end of this decade however, Canada took a major turn adopting "anti-racist, pro-human rights" value and introduced a new immigrant selection and integration approach. Until the end of the twentieth century immigrant selection was based on: human capital assets, family ties, or humanitarian reasons. $[77,78]$ Since the beginning of the 21st century, the country's immigration policy took a new direction, aligning itself with a neoliberal political economic approach which influenced immigrant selection and integration based on "free market" economic principles. During the previous Conservative regime immigration policy was geared towards "promoting corporate profitability and reducing federal government expenses". [78 p107] Under this neoliberal perspective, refugees and asylum seekers are considered "expensive newcomers" who take advantage of Canada's healthcare and social support services.[78 p108]

Yet research indicates that immigrants, especially those with chronic diseases, use fewer healthcare resources than native-born, although they have coverage under the country's universal health insurance scheme (universality refers to the entitlement of all eligible residents to insured services). $[35,79,80]$ It should be noted however, there are a number of uninsured medical services deemed of less "medical necessity".[81] Among the mental healthcare services not covered or partially covered by provincial health insurance plans, and identified as systemic barriers to accessing care, are counselling services and mainstream community health services. For immigrants with precarious employment, the difficulty of taking time off work to access care adds to the challenge of service utilization.[82] Immigrants' utilization of health services in general is also affected by the inability to access primary care physicians, long waiting times for diagnosis and treatment, as well as a mandatory waiting time to enroll in a provincial health insurance plan.[81] Other than individual factors, such as lack of awareness of mental health issues, a prolonged state of having a low income and social exclusion, as well as inadequate culturally appropriate services, are prominent barriers to the use of mental health services among Ethiopian, Chinese and South Asian immigrants in Canada.[83-85]

This paper translated the scientific evidences reported the Symposium presenters and their research program and also partially conveyed the ideas exchanged among them and the attendees. The summary of the multiple sets of ideas transformed as knowledge has limitations. The first limitation refers to the short duration of dialogue among the participants about possibility, limitations and challenges regarding the transfer of the shared knowledge between Paris and Toronto researchers and practitioners that may restrain knowledge applicability to the field. The second limitation refers to noaccess to primary research data that limited our interpretation of the full extent of the reported evidences as components of the presenters' material.

\section{Future research recommendations}

As discussed earlier, although overall mental health service utilization is low among immigrants, evidence suggests access to care is disproportionately even lower among immigrant women, children, adolescents, and seniors.[8] For instance, although immigrant women are two to three times at greater risk for postpartum depression compared to their native-born 
counterparts, they displayed reluctance in seeking services or disclosing their emotional state to non-family members.[8]

Foreseeing new studies in collaboration among researchers located in Paris and Toronto, Symposium participants who were interested in the theme "Mental Health and Immigration" wanted to explore it in the context of sex and gender. Several new research topics were proposed, which undoubtedly will require a multidisciplinary research team. Table 3 introduces a new research agenda for this scholarly joint work.

Knowledge exchanged during the Symposium and corroborated by research evidence shows that economic disparities, societal and political forces, as well as cultural and linguistic factors, underpin immigrants' and refugees' mental health stability. There is a growing trend and discourse to recognize culture and cultural diversity in care delivery models.[86] Yet, this trend has limitations in practice to sensitize and educate social and health professionals beyond a biomedical reductionist approach. As mental health instability in this population is related to larger structural forces, individual experiences are articulated in unique ways. A socially diverse, multidisciplinary care delivery approach is a sensible responsive alternative.

Readers are warned to consider a questionable success of medical anthropology to do so. While anthropology as a discipline may have had little impact on medicine thus far, the growing popularity of $\mathrm{MD} / \mathrm{PhD}$ programs over the past two decades, for which anthropology constitutes the second top choice as selected $\mathrm{PhD}$ discipline (chosen by $22 \%$ of MD/ PhDs) seems to highlight a change of direction.[87] In fact, a recent survey reports that: "In general, MD-PhDs in the social sciences and humanities have careers that fit the goals of agencies providing public funding for training physicianinvestigators: they are involved in mutually-informative medical research, clinical practice, and teaching -working to improve our responses to the social, cultural, and political determinants of health and health care".[87] In that perspective, we have yet to measure how the "clinical gaze" evolves in the coming years, as physicians trained in anthropology and in other social sciences hold important leadership positions in health institutions (such as Jim Yong Kim, President of the World Bank, or Camara Jones, Medical Officer at the Center for Disease Control and Prevention and President of the American Public Health Association), and as global health approaches continue to flourish in medical training programs around the globe.

Additionally, programs for undergraduate health students have shown promise in raising critical awareness of structural vulnerabilities and their impact on health outcomes. Whereas previous research has tended to focus on medical students and junior doctors, recent studies have identified that by learning concepts in medical anthropology, such as structural vulnerability, undergraduate health students may be better suited to identify racial disparities in conditions such as heart disease and childhood obesity.[88,89] These anthropological concepts undergraduate students learn reflect the kinds of values and skills that educational bodies, such as the Medical College Admissions Test (MCAT) and the American Association of Medical Colleges (AAMC), consider to be core competencies. Clinicians trained in concepts in medical anthropology have also demonstrated the ability to respond to the ways that structural discrimination manifests in patients. For instance, Hansen and colleagues[90] identify how psychiatrists trained in structural competency and cultural humility, for example, have successfully addressed the mental health effects of hate crimes based on race, sexuality, religion, immigration status, and their intersections.

\section{References}

1.United Nations. International Migration Report. New York: Department of Economic and Social Affairs/Population Division 2017. Available from: http://www.un.org/en/ development/desa/population/migration/publications/ migrationreport/docs/MigrationReport2017.pdf. Accessed 28 November 2017.

2.Statistic Canada. Immigrant population in Canada, 2016 Census of Population. Oct 2017. Available from: https:// www150.statcan.gc.ca/n1/pub/11-627-m/11-627m2017028-eng.htm Accessed 27 March 272018.

3.Institut national de la statistique et des études économiques. Population Étrangère et Immigrée en France en 2015 Données Annuelles de 1921 à 2015. Institut national de la statistique et des études économiques 2018. Available from: https://www.insee.fr/fr/statistiques/2381757. Accessed 9 June 2018.

4.Institut national de la statistique et des études économiques. Répartition des Étrangers par Nationalité en 2015. Institut national de la statistique et des études économiques 2018. Available from: https://www.insee.fr/fr/ statistiques/2381750. Accessed 9 June 2018.

5.Office français de protection des réfugiés et apatrides. 2018. Les Données de l'Asile 2017 à l'OFPRA. Paris: Office français de protection des réfugiés et apatrides. Available from: https://www.ofpra.gouv.fr/fr/l-ofpra/actualites/lesdonnees-de-l-asile-2017-a-I. Accessed 9 June 2018.

6.McKenzie K, Agic B, Tuck A, Antwi M. The Case for Diversity: 
Building the Case to Improve Mental Health Services for Immigrant, Refugee, Ethno-cultural and Racialized Populations. Ottawa: Mental Health Commission of Canada 2016. Available from: https://www.mentalhealthcommission.ca/sites/ default/files/2016-10/case_for_diversity_oct_2016_eng.pdf. Accessed 23 March 2018.

7.Das-Munshi J, Leavey G, Stansfeld SA, Prince MJ. Migration, social mobility and common mental disorders: critical review of the literature and meta-analysis. Ethnicity \& Health 2013; 17(1-2): 17-53.

8.Kirmayer $\sqcup$, Narasiah L, Munoz M, Rashid M, Ryder AG, Guzder J, et al. Common mental health problems in immigrants and refugees: general approach in primary care. Canadian Medical Association Journal 2011; 183(12): E959-E967.

9.Robert A, Gilkinson T. Mental Health and Well-Being of Recent Immigrants in Canada: Evidence from the Longitudinal Survey of Immigrants to Canada. Immigrant Integration (LSIC): Government of Canada 2012. Available from: https://www. canada.ca/en/immigration-refugees-citizenship/corporate/ reports-statistics/research/mental-health-well-being-recentimmigrants-canada-evidence-longitudinal-survey-immigrantscanada-Isic.html. Accessed 28 March 2018.

10.Islam F, Khanlou N, Tamim H. South Asian populations in Canada: migration and mental health. BMC Psychiatry 2014; 14(154): 1-13.

11.Thomson MS, Chaze F, George U, Guruge S. Improving immigrant populations' access to mental health services in Canada: a review of barriers and recommendations. Journal of Immigrant and Minority Health 2015, 17(6): 1895-1905.

12. Hacker K, Anies M, Folb BL, Zallman L. Barriers to health care for undocumented immigrants: a literature review. Risk Management and Healthcare Policy 2015; 8: 175-83.

13.Desgrées du Loû A, Lert F. Parcours: Parcours de Vie et Santé des Africains Immigrés en France. Paris : La Découverte, 2017.

14.Comité pour la santé des exilés. Rapport d'observation et d'activité du Comède. Rapports annuels. Paris: Comité pour la santé des exilés 2017. Available from: http://www.comede. org/rapport-dactivite/. Accessed 9 June 2018.

15.Tortelli A, Skurnik N, Szöke A, Simon P. L'importance de la recherche épidémiologique psychiatrique sur les populations migrantes en France. Annales Médico-Psychologiques, Revue Psychiatrique 2017; 175(6): 577-82.

16.Guardia D, Salleron J, Roelandt JL, Vaïva G. Prévalence des troubles psychiatriques et addictologiques auprès de trois générations successives de migrants: résultats d'une étude menée en population générale. L'Encéphale 2007; 43(5): 435-43.

17.Chambon N, Le Goff G. Enjeux et controverses de la prise en charge des migrants précaires en psychiatrie. Revue Française des Affaires Sociales 2016; 2: 123-40.

18.Fernández A, Rodriguez RA. Undocumented immigrants and access to health care. Journal of the American Medical Association - Internal Medicine 2017; 177(4): 536-7.

19.Médecins du Monde. Legal Report on Access to Healthcare in 12 Countries. Paris: Médecins du Monde 2015. Available from: https://mdmeuroblog.files.wordpress.com/2014/05/ mdm-legal-report-on-access-to-healthcare-in-12-countries3rd-june-20151.pdf. Accessed 5 April 2018.

20.National Association of County and City Health Officials. Statement of Policy: The Health of Documented and Undocumented Immigrants. Washington: NACCHO 2013. Available from: http://archived.naccho.org/advocacy/ positions/upload/99-02-Health-of-Documented-andUndocumented-Immigrants.pdf. Accessed 9 June 2018.

21.Siemons R, Raymond-Flesh M, Auerswald CL, Brindis CD. Coming of age on the margins: mental health and wellbeing among Latino immigrant young adults eligible for Deferred Action for Childhood Arrivals (DACA). Journal of Immigrant and Minority Health 2017; 19(3): 543-51.

22.Agic B, McKenzie K, Tuck A, Antwi, M. Supporting the Mental Health of Refugees to Canada. Mental Health Commission of Canada 2016. Available from: https:// www.mentalhealthcommission.ca/sites/default/ files/2016-01-25_refugee_mental_health_backgrounder_0. pdf. Accessed 25 March 2018.

23.Anderson KK, Cheng J, Susser E, McKenzie KJ, Kurdyak $P$. Incidence of psychotic disorders among first-generation immigrants and refugees in Ontario. Canadian Medical Association Journal 2015; 9: E279-E286.

24.Haas BM. Suffering and the Struggle for Recognition: Lived Experiences of the U.S. Political Asylum Process [Dissertation]. San Diego: University of California San Diego; 2012. 469 p. Available from: http://escholarship.org/uc/ item/7pdOw87k\#page-483. Accessed 28 July 2020.

25.El-Shaarawi N. Living an uncertain future: temporality, uncertainty and well-being among Iraqi refugees in Egypt. Social Analysis 2015; 59(1): 38-56.

26.Larchanché S. Cultural Anxieties: Managing Migrant Suffering in France.1st ed. New Brunswick: Rutgers University 
Press, 2020.

27.Castañeda H, Holmes SM, Madrigal DS, Young M ED, Beyeler N, Quesada J. Immigration as a social determinant of health. Annual Review of Public Health 2015; 36: 375-92.

28.Quesada J, Hart LK, Bourgois P. Structural vulnerability and health: Latino migrant laborers in the United States. Medical Anthropology 2011; 3 (4): 339-62.

29.Kirmayer L, Guzder J, Rousseau C. (eds). Cultural Consultation: Encountering the Other in Mental Health Care. Springer, 2014.

30.Kleinman A, Benson P. Anthropology in the clinic: the problem of cultural competency and how to fix it. PLoS Medicine 2006; 3(10): e294.

31.Metzl JM, Hansen H. Structural competency: theorizing a new medical engagement with stigma and inequality. Social Science \& Medicine 2014; 103: 126-33.

32. Hansen H, Braslow J, Rohrbaugh RM. From cultural to structural competency-training psychiatry residents to act on social determinants of health and institutional racism. JAMA Psychiatry. 2018; 75(2): 117-8.

33.Paillé P, Mucchielli A. L'Analyse Qualitative en Sciences Humaines et Sociales. (4e-éd.). Paris: Armand Colin, 2016.

34.Silva MA, Paris M, Añez LM. CAMINO: Integrating context in the mental health assessment of immigrant Latinos. Professional Psychology: Research and Practice 2017; 48(6): 453-60.

35.Newbold KB. Self-rated health within the Canadian immigrant population: risk and the healthy immigrant effect. Social Science \& Medicine 2005; 60(6): 1359-70.

36.Carpenter-Song EA, Schwallie MN, Longhofer J. Cultural competence reexamined: critique and directions for the future. Psychiatric Services 2007; 58(10): 1362-5.

37.Santiago-Irizarry V. Medicalizing ethnicity: The Construction of Latino Identity in a Psychiatric Setting. Cornell University Press, 2001.

38.Good MD, Willen SS, Hannah SD, Vickery K, Park LT. Shattering Culture: American Medicine Responds to Cultural Diversity. Russell Sage Foundation, 2011.

39. Kirmayer LJ. Rethinking cultural competence. Transcultural Psychiatry 2012; 49(2): 49-64.

40.Willen SS, Carpenter-Song E. Cultural competence in action: "Lifting the hood" on four case studies in medical education. Culture, Medicine, \& Psychiatry 2013; 37(2): 241-52.
41. Hickling FW, Paisley V. Issues of clinical and cultural competence in Caribbean migrants. Transcultural Psychiatry 2012; 49(2): 223-44.

42.Kai J, Beavan J, Faull C, Dodson L, Gill P, Beighton A. Professional uncertainty and disempowerment responding to ethnic diversity in health care: a qualitative study. PLoS Medicine 2007; 4(11): e323.

43.Fox RC. Training for uncertainty. In: Merton R, Reader G, Kendall $\mathrm{P}$ (eds). The Student Physician: Introductory Studies in the Sociology of Medical Education. Cambridge: Harvard University Press, 1957.

44.Parsons T. The Social System. London: Routledge, 1991.

45.Sargent C, Larchanché S. The construction of "cultural difference" and its therapeutic significance in immigrant mental health services in France. Culture, Medicine, and Psychiatry 2009; 33(1): 2-20.

46.Paris C. Association Françoise et Eugène MinkowskiCentre Françoise Minkowska-Parcours de soin et santé mentale. European Psychiatry 2018; 30(8): 86-87.

47.Larchanché S. MEDIACOR: médiation, accueil et orientation des populations migrantes et réfugiées. Perspectives sanitaires et sociales. Cahiers de l'innovation 2014; 44: e114. Available from: http://novap.fehap.fr/candidats/mediacormediation-accueil-orientation-populations-migrantesrefugiees/. Accessed 9 June 2019.

48.Kleinman, A. The IIIness Narratives: Suffering, Healing, and the Human Condition. New York, Basic Books, 1989.

49.Bennegadi R. Cultural competence and training in mental health practice in Europe: Strategies to implement competence and empower practitioners. International Organization of Migration. Background paper 2009. Available from: http:// www.minkowska.com/sites/default/files/mental_health_ practice_background_paper1.pdf. Accessed 9 June 2018.

50.Cutter SL, Finch C. Temporal and spatial changes in social vulnerability to natural hazards. Proceedings of the National Academy of Sciences 2008; 105(7):2301-6. Available from https://www.pnas.org/content/105/7/2301. Accessed 9 June 2018.

51.Farmer P. On suffering and structural violence: a view from below. Daedalus 1997; 125(1): 261-83.

52.Fox R C. Cultural competence and the culture of medicine. The New England Journal of Medicine 2005; 353(13): 1316-9.

53.Jenks AC. From "lists of traits" to "open-mindedness": emerging issues in cultural competence education. Culture, 
Medicine, and Psychiatry 2011; 35(2): 209-35.

54.Shaw S J, Armin J. The ethical self-fashioning of physicians and health care systems in culturally appropriate health care. Culture, Medicine, and Psychiatry 2011; 35(2): 236-61.

55.Castañeda H. "Over-foreignization" or "Unused potential”? A critical review of migrant health in Germany and responses toward unauthorized migration. Social Science \& Medicine 2012; 74(6): 830-8.

56. Holmes S. Fresh fruit, broken bodies: Migrant farmworkers in the United States. University of California Press, 2013.

57.Betancourt JR, Green AR, Carrillo JE, Ananeh-Firempong O. Defining cultural competence: a practical framework for addressing racial/ethnic disparities in health and health care. Public Health Reports 2003; 118(4): 293-302.

58.Kumagai AK, Lypson ML. Beyond cultural competence: critical consciousness, social justice, and multicultural education. Academic Medicine 2009; 84(6): 782-87.

59.Fisher-Borne M, Cain JM, Martin SL. From mastery to accountability: cultural humility as an alternative to cultural competence. Social Work Education 2015; 34(2): 165-81.

60.Hook JN, Davis DE, Owen J, Worthington Jr EL, Utsey SO. Cultural humility: measuring openness to culturally diverse clients. Journal of Counseling Psychology 2013; 60(3): 35366.

61.Tervalon M, Murray-Garcia J. Cultural humility versus cultural competence: a critical distinction in defining physician training outcomes in multicultural education. Journal of Health Care for the Poor and Underserved 1998; 9(2): 117-25.

62.Sue S, Fujino DC, Hu LT, Takeuchi DT, Zane NW. Community mental health services for ethnic minority groups: a test of the cultural responsiveness hypothesis. Journal of Consulting and Clinical Psychology 1991; 59(4): 533-40.

63.Ali A, Sichel CE. Structural competency as a framework for training in counseling psychology. The Counseling Psychologist 2014; 42: 901-18.

64.Coutin SB. Deportation studies: origins, themes and directions. Journal of Ethnic and Migration Studies 2015; 41(4): 671-81.

65.Drotbohm H, Hasselberg I. Deportation, anxiety, justice: new ethnographic perspectives. Journal of Ethnic and Migration Studies 2015; 41(4): 551-62.

66.Fassin D. Policing borders, producing boundaries. The governmentality of immigration in dark times. Annual Review of Anthropology 2011; 40: 213-26.

67.Larchanché S. Intangible obstacles: health implications of stigmatization, structural violence, and fear among undocumented immigrants in France. Social Science \& Medicine 2012; 74(6): 858-63.

68.Geeraert J. Healthcare reforms and the creation of ex/ included categories of patients-“irregular migrants" and the "undesirable" in the French healthcare system. International Migration 2018; 56(2): 68-81.

69.Fassin D, Kobelinsky C. Comment on juge l'asile. Revue française de sociologie 2012; 53(4): 657-88.

70.Le Défenseur des droits. Les Droits Fondamentaux des Étrangers en France. Paris: Le Défenseur des droits 2016. Available from: https://www.defenseurdesdroits.fr/sites/ default/files/atoms/files/736160170_ddd_rapport_droits_ etrangers.pdf. Accessed 9 June 2019.

71.d'Halluin E. La santé mentale des demandeurs d'asile. hommes \& migrations. Revue française de référence sur les dynamiques migratoires 2009; 1282: 66-75.

72.Chambon N, Zeroug-Vial H, Carbonel N. L'interprétariat en santé mentale: les enjeux de la formation. L'Autre 2017; 18(3): 362-68.

73.Comité pour la santé des exilés. Soins et Accompagnement Migrants/Étrangers en Situation Précaire. Guide Comède. Paris: Comité pour la santé des exilés 2015. Available from: https://www.comede.org/guide-comede/. Accessed 9 June 2018.

74.Sainte Marie CF, Querrioux I, Baumann C, Di Patrizio P. Difficultés des médecins généralistes dans la prise en charge de leurs patients précaires. Santé Publique 2015; 27(5): 67990.

75.de Feraudy J M, Petrouchine R, Monet A. Le migrant précaire et le psychiatre en libéral. Des pratiques aux marges pour un public à la marge? Rhizome 2017; (1): 50-6.

76.Shields J, Bauder H. Immigrant Experiences in North America: Understanding Settlement and Integration. Canadian Scholars' Press, 2015.

77.George U, Chaze F, Doyle R. Immigration and settlement in Canada. BookSurge Publishing, 2007.

78.Siemiatycki M. Continuity and change in Canadian immigration policy. In: Bauder H, Shields J (eds). Immigration Experiences in North America. Canadian Scholars Press, 2015; 93-117. 
79.Beiser $M$. The health of immigrants and refugees. In: Bauder $\mathrm{H}$, Shields J (eds). Immigrant Experiences in North America: Understanding Settlement and Integration. Canadian Scholars' Press, 2015; 312-42.

80.Beiser M, Hou F. Chronic health conditions, labour market participation and resource consumption among immigrant and native-born residents of Canada. International Journal of Public Health 2014; 59(3): 541-47.

81.Wang L. Immigrant health services and health care. In: Bauder $\mathrm{H}$, Shields J (eds). Immigrant Experiences in North America: Understanding Settlement and Integration. Canadian Scholars' Press, 2015; 343-66.

82.Salami B, Salma J, Hegadoren K. Access and utilization of mental health services for immigrants and refugees: perspectives of immigrant service providers. International Journal of Mental Health Nursing 2019; 28(1): 152-61.

83.Fenta H, Hyman I, Noh S. Health service utilization by Ethiopian immigrants and refugees in Toronto. Journal of Immigrant and Minority Health 2007; 9(4): 349-57.

84.Lai DW, Surood S. Types and factor structure of barriers to utilization of health services among aging South Asians in Calgary, Canada. Canadian Journal on Aging 2010; 29(2): 249-58.

85.Thomson MS, Chaze F, George U, Guruge S. Improving immigrant populations' access to mental health services in Canada: a review of barriers and recommendations. Journal of Immigrant Minority Health 2015; 17(6):1895-905.

86. Hansson E, Tuck A, Lurie S, McKenzie K, for the Task Group of the Services Systems Advisory Committee, Mental Health Commission of Canada. Improving mental health services for immigrant, refugee, ethno-cultural and racialized groups: issues and options for service improvement. 2010. Available from: http://www.mentalhealthcommission.ca/ SiteCollectionDocuments/Key_Documents/en/20 10/ Issues_Options_FINAL_English\%2012Nov09.pdf. Accessed 9 June 2018.

87. Holmes SM, Karlin J, Stonington SD, Gottheil DL The first nationwide survey of MD-PhDs in the social sciences and humanities: training patterns and career choices. BMC Medical Education 2017; 17(60). https://doi.org/10.1186/ s12909-017-0896-1

88.Metzl, JM, Petty, J. Integrating and assessing structural competency in an innovative prehealth curriculum at Vanderbilt University. Academic Medicine 2017; 92(3): 354359. doi:10.1097/ACM.0000000000001477
89.Petty J, Metzl JM, Keeys MR. Developing and evaluating an innovative structural competency curriculum for pre-health students. Journal of Medical Humanities 2017; 38(4): 459471. doi: 10.1007/s10912-017-9449-1

90. Hansen H, Riano NS, Meadows T, Mangurian C. Alleviating the mental health burden of structural discrimination and hate crimes: the role of psychiatrists. American Journal of Psychiatry 2018; 175(10): 929-933. https://doi.org/10.1176/ appi.ajp.2018.17080891

Acknowledgements

The authors thank Dr. Gesine Sturm for reviewing the early draft of this manuscript and Dr. Sylvia Novac for editing it. The Symposium was possible due to funding provided by Ryerson University, Consulat Général de France à Toronto, Institut Humanités \& Sciences de Paris, INSERM-Instituts thématiques, and Université Paris SorbonneCité. Local sponsors were Canadian Nursing Students AssociationRyerson Chapter, Collège Boréal de Toronto, Centre Francophone de Toronto, and Reflet Salvéo - French-Language Health Planning Entity. Publication was supported by Ryerson University, Faculty of Community Services-Writing Week Initiative.

To contact the authors:

Margareth Santos Zanchetta, Ph.D.

Ryerson University

Daphne Cockwell School of Nursing

Faculty of Community Services

288 Church St. office DCC 539

Toronto, ON M5B $1 Z 5$

Canada

E-mail: mzanchet@ryerson.ca

Abinet Gebremariam, M.A.

Ryerson University

Daphne Cockwell School of Nursing

Faculty of Community Services

David Aftab Ansari, Ph.D.

The University of Chicago

Department of Comparative Human Development

Elizabeth Huang, M.A.

Ryerson University

Daphne Cockwell School of Nursing

Faculty of Community Services,

Stéphanie Larchanché, Ph.D.

Université Sigmund Freud

Centre Minkowska and Sigmund Freud

Clément Picot-Ngo, Ph.D.(c)

Université Paris-Diderot

Faculté de Médecine

Marguerite Cognet, Ph.D.

Université de Paris 7 (Paris-Diderot)

Laboratoire URMIS (UMR IRD \& CNRS)

IHSS, Département de sciences sociales

Shone John, M.D.

Royal Shrewsbury Hospital 